\title{
ETIKA DAN ESTETIKA MEUDIKEE ANGGOK DI DAYAH DARUL HUDA DESA BAYI KECAMATAN TANAH LUAS LHOKSUKON KABUPATEN ACEH UTARA
}

\author{
Erna Fitriyawati ${ }^{1}$, Iskandar Muda ${ }^{2}$ \\ Prodi Pendidikan Tari/ Fakultas Bahasa dan Seni/ Universitas Negeri Medan \\ Jalan Willem Iskandar Pasar V Medan Estate 20221, Sumatera Utara-Indonesia \\ Iernafitriyawati@yahoo.com, ${ }^{2}$ cendana@unimed.ac.id
}

\begin{abstract}
This study discusses the Value of Ethics and Aesthetics Meudikee Anggok In Dayah Darul Huda Bayi Village District Lhoksukon District Luas Aceh. Aims to describe Ethical and Esthetic Value of Meudikee Anggok In Dayah Darul Huda Bayi Village, Lhoksukon Sub-district, Lhokukon District, Aceh. The theory used in this study is the ethical theory of K. Bertens According to K. Bertens The ethical theory according to K. Bertens (1993: 53) that ethics is the conscience (inner life), how to be ethical and good that actually arise from self awareness. Based on the theory of K. Bertens concluded that every human being has experience of the conscience and that experience is the most obvious encounter with morality as a reality, it is difficult to show another experience that is so frankly the ethical dimension of our lives. Hence the experience of the conscience is an appropriate entry point about ethics. Time in use in this study is during (two months), ie from July to September. The location of this research was conducted in Bayi Village, North Aceh District. The population in this study are artists who know about Meudikee Anggok dance, and the sample is Aneuk Dikee (son of Zikir). The research data analysis used is descriptive qualitative, data collecting technique done by obsevasi, literature study, interview, and documentation. Based on the data collected, it can be seen that Meudikee Anggok has been known for a long time. The number of boys who performed Meudikee Anggok at the beginning of choreographer formation was 16 Aneuk Dikee and 4 syeh (radad). Meudikee anggok has ethical values contained in the ethics of movement 1. Respect 2. Saleum. 6. Noble Prophets and 7. Prayers. Aesthetic value that can be observed every movement at 3. Istigfar, 4. Salawat prophets and 5. Qasas.
\end{abstract}

Keywords: Meudikee Anggok Di Dayah darul Huda Deswa Bayi Kecamatan Luas Lhoksukon Kabupaten Aceh Utara,Ethics and Aesthetics.

\section{PENDAHULUAN}

"Meudikee Anggok berasal dari bahasa Aceh yaitu berdzikir sambil menggangguk, di dalam agama Islam berdzikir adalah aktivitas menyebut asma Allah SWT. Bertujuan untuk mendekatkan diri kepadanya, dengan membaca doa bersalawat, memohon ampunan kepada Allah SWT, untuk selalu mengingat akan kekuasaan dan kebesarannya sehingga kita bisa terhindar dari hal-hal buruk didunia. Adapun jenis-jenis Meudikee yaitu: Meudikee Rayeuk adalah dzikir selesai sholat secara bershaf dipimpin oleh satu orang yang juga berada dalam satu shaf dzikir, dilakukan oleh orang tua atau orang dewasa. Meudikee Anggok adalah Meudikee yang hanya dipelajari ditempat pengajian (Dayah). Meudikee Poh Kipah adalah Meudikee untuk menyambut para raja dan tamu-tamu agung".

Pada penelitian ini Meudikee Anggok dilakukan pada hari kelahiran nabi Muhammad SAW. Kata Dike di dalam bahasa Aceh setempat berarti zikir, pada hari kelahiran nabi Muhammad SAW. Perayaan memperingati hari kelahiran nabi Muhammad SAW, merupakan tradisi yang berkembang di masyarakat Islam jauh setelah nabi Muhammad SAW 
wafat.Peringatan ini adalah kegembiraan dan penghormatan kepada nabi Muhammad SAW. Sususnan Dalail khairat dalam Meudikee yaitu :

1. Kalam Allah SWT (perkataan Alah swt dalam $\mathrm{Al}$-qur'an yang dibaca satu sampai dua ayat lalu Al-Fatihah).

2. Saleum (memberikan salam).

3. Istigfar (melantunkan kalimat-kalimat Allah SWT).

4. Salawat Nabi (puji-pujian untuk nabi Muhammad SAW).

5. Qasas (cerita yang mengandung pesan yang baik pada zaman nabi Muhammad SAW).

6. Mulia Nabi (membaca Shalawat Badar).

7. Doa (meminta suatu harapan).

Dikee Moloed adalah seremonial atau keseluruhan dari acara, karena adanya penyusunangerak, penyusunanpola,dan memiliki makna". Meudikee Anggok didalam bahasa Aceh berarti berzikir sambil angguk kepala, dipelajari di tempat pengajian (Dayah). Pada masyarakat Lhoksukon Aceh Utara Meudikee Anggok bukan hanya sebagai aktivitas keagamaan, tetapi juga sebuah seni yang fungsinya sebagai syiar agama, kepada masyarakat tentang perjuangan nabi Muhammad SAW, dalam memperjuangkan agama Islam. Meudikee Anggok dipelajari agar anak-anak semakin mengetahui tentang Islam untuk menghindari masuknya budaya-budaya asing yang tidak mengikuti syariat Islam.

Lokasi penelitian dilaksanakan di Dayah Darul Huda Desa Bayi Kecamatan Tanah Luas Lhoksukon Kabupaten Aceh Utara, alasannya memilih lokasi ini dikarenakan banyaknya seniman yang mengetahui tentang Meudikee Anggok dan kesenian asli Aceh yang berdomisili didaerah tersebut. Lokasi inidipilih agar dapat terhubung langsung dengan narasum berserta penari yang mengetahui Meudikee Anggok. Penelitian secara dokumentasi dan wawancara. Waktu yang diperlukan dalam penelitian ini untuk mendapatkan data, dilaksanakan pada bulan Juni sampai September 2018. Populasi yang digunakan terbatas dan dapat dijadikan sumber data dalam penelitian. Oleh karena itu, yang menjadi populasi dalam penelitian ini adalah masyarakat di Dayah Darul Huda Desa Bayi Kecamatan Tanah Luas Lhoksukon Kabupaten Aceh Utara.

$$
\text { Menurut Sugiyono }
$$
menyatakan bahwa "sampel adalah bagian dari jumlah dan karakteristik yang dimiliki oleh populasi tersebut. Bila populasi besar, dan peneliti tidak mungkin mempelajari semua yang ada pada populasi”. Dalam penelitian ini, yang dijadikan sampel adalah beberapa pelaku atau penari Medikee Anggok di Dayah Darul Huda Desa Bayi Kecamatan Tanah Luas Lhoksukon Kabupaten Aceh Utara.

Adapun Teknik pengumpulan data yang dilakukan adalah sebagai berikut: 1. Observasi, 2. Wawancara, 3. Dokumentasi, 4. Studi Kepustakaan. Dalam Penelitian ini data yang digunakan adalah deskriptif kualitatif dimana penelitian ini sesuai dengan fakta sosial dan memberi gambaran, keterangan serta uraian.

\section{HASIL DAN PEMBAHASAN.}

\section{Asal Mula Meudikee Anggok}


Meudikee Anggok merupakan bagian dari Dikee Moelod (dzikir maulid), Dikee Moelod merupakan sebuah perayaan hari kelahiran nabi Muhammad SAW. Islam di Aceh yang dilakukan pada perayaan hari kelahiran nabi Muhammad SAW (Maulid) yang mempunyai urutan dan lantunan yang harus dibaca dan dilakukan secara sistematis. Meudikee terbagi atas 3 jenis yaitu Meudikee Poh Kipah yaitu Meudikee yang dilakukan pada zaman dahulu didepan para raja, Meudikee Rayeuk yaitu meudikee yang dilakukan selesai shalat yang dilakukan oleh orang dewasa, dan Meudikee Anggok yang dipertunjukkan hanya pada bulan Maulid sebagai ungkapan rasa cinta umat Islam kepada nabi Muhammad SAW. Beristighfar dan bershalawat kepada nabi Muhammad SAW yang dilakukan dengan khusyuk adalah rasa berserah diri memohon ampunan kepada Allah SWT. Asal mula Meudikee Anggok berasal dari Arab, dan dikembangkan di Aceh. Meudikee artinya berdzikir, dalam kehidupan masyarakat Aceh Utara, Meudikee (berdzikir) merupakan sebuah aktivitas ibadah umat muslim untuk menginggat Allah SWT dengan cara membaca doa, menyebut asma Allah SWT dan Meudikee Anggok adalah berzikir sambil angguk kepala.

Berfungsi sebagai media dakwah dalam mensyiarkan agama Islam. Dengan demikian Meudikee Anggok adalah berdzikir dengan menganggukkan kepala. Meudikee Anggok merupakan tari tradisional masyarakat Aceh Utara, Gerak Meudikee Anggok berpijak dari gerakan berdzikir selesai shalat, mengganggukkan kepala kekanan dan kiri dan menghayunkan badan secara perlahan dalam posisi duduk bersila. Meudikee Anggok merupakan tari yang hanya dipertunjukkan pada hari kelahiran nabi Muhammad SAW yaitu pada tanggal 12 Rabiul Awal, yang biasa disebut dengan hari Maulid sebagai ungkapan rasa syukur kepada Allah SWT yang telah memberikan nabi pembawa rahmat yang menuntun kejalan Allah SWT.

\section{A. Etika Dalam Meudikee Anggok}

Etika dalam Meudikee Anggok dapat kita amati dari gerakan Meudikee Anggok. Meudikee Anggok mempunyai batasan-batasan gerak, maksudnya dalam menggerakkanya tidak berlebihan tetapi sesuai dengan gerak yang seharusnya yaitu menggoyangkan kepala dan bahu tidak berlebihan. Etika adalah nurani (bathiniah), bagaimana harus bersikap etis dan baik yang sesungguhnya timbul dari kesadaran dirinya”. Jika dikaitkan dengan penelitian ini tentang Meudikee Anggok maka akan membahas tentang etika gerak Meudikee Anggok, busana Meudikee Anggok dan syair Meudikee Anggok.

\section{Gerak}

\section{Penghormatan pembuka (Kalam Allah SWT)}

Penghormatan adalah proses, cara, perbuatan menghormati, dan pemberian hormat. Penghormatan biasanya ditujukan kepada tuhan yang maha Esa, raja-raja yang dituakan.Namun pada gerak Kalam Allah SWT penari dalam keadaan diam dan khusyu'.

\section{Saleum (salam)}


Gerakan salem hanya menunduk menunjukan penghormatan kepada perangkat kampung yang telah berpartisifasi untuk merayakan hari kelahiran nabi Muhammad SAW.

\section{Istigfar}

Istigfar juga salah satu manusia mengingat akan dosa dan menunjukan bahwa agar anak-anak menghayati dan merasakan bahwasannya dunia ini tidak kekal, maka mereka melakukannya dengan bersungguhsungguh bergerak dengan rasa cinta mereka kepada Allah SWT dan nabi Muhammad SAW.

\section{Shalawat Nabi}

Gerak pada shalawat nabi merupakan gerak yang sudah mengangguk karena mereka bergerak dengan rasa di dalam hati pada pengetahuan yang mereka dapat.

\section{Qasas}

Pada gerakan qasas menunjukan bahwasannya mereka mengenang kisah nabi Muhammad yang berjuang untuk umat Islam.6.

\section{Mulia Nabi}

Pada gerakan Mulia Nabi yaitu bergerak menyesesuaikan dengan lantunan-lantunan yang disyairkan dalam keadaan berdiri diam (khusyu'),

\section{Doa Penutup}

Penghormatan penutup adalah proses, cara, perbuatan menghormati Penghormatan biasanya ditunjukan kepada tuhan yang maha Esa, raja-raja yang dituakan.

\section{Busana}

Ditinjau dari aspek biologis busana yaitu untuk melindungi tubuh dari cuaca, sinar matahari, debu, serta yang lainnya. Busana juga untuk menutupi atau menyamarkan kekurangan dari pemakaian, busana juga dapat menambah percaya diri dalam melakukan aktivitas.

\section{a. Baju koko lengan panjang}

Etika di dalam busana baju koko lengan panjang yaitu baju koko menunjukan suatu pakaian dipandang menutup aurat,

\section{b. Peci}

Etika di dalam memakai peci meudikee anggok, seperti yang sudah kita ketahui bahwa segala macam penutup kepala untuk pria itu sunnah Rasul.

\section{c. Sarung}

Etika pemakaian sarung di dalam Meudikee Anggok menyimbolkan kesopanan.

\section{Syair}

Syair digunakan untuk melukiskan halhal yang panjang, misalnya tentang suatu cerita, nasehat, agama, cinta dan lain-lain dan syair adalah sebagai ekspresi perasaan atau pikiran yang membuatnya.

1. Kalam Allah SWT

2. Saleum (Salam)

3. Istigfar

4. Shalawat Nabi

5. Qasas.

6. Mulia Nabi

7. Doa

\section{B. Estetika Dalam Meudikee Anggok}

Estetika Meudikee Anggokcinta kasih karena ada kecintaan, maka manusia selalu ingin kembali menikmati apa yang dicintainya itu. Rasa cinta pada manusia ini bukan hanya tertuju pada keindahan, tetapi juga kebaikan (moral) dan kebenaran (ilmu pengetahuan)". Salah satu 
tari tradisi yang dimiliki oleh masyarakat suku Aceh, Meudikee Anggok dipersembahkan pada acara memperingati hari kelahiran nabi Muhammad SAW. Seiring berkembangnya zaman, Meudikee Anggok tidak pernah lepas dari keasliannya dan tetap mempertahankan yang menjadi dasar dari tarian tersebut, yaitu berupa gerak, busana dan syair.

1. Penghormatan pembuka (Kalam Allah SWT )

2. Saleum (salam)

3. Istigfar

4. Shalawat Nabi

5. Qasas

6. Mulia Nabi

7. Doa Penutup

\section{PENUTUP}

\section{Kesimpulan}

1. Meudikee berasal dari bahasa Aceh yaitu berdzikir,di dalam agama Islam berdzikir adalah aktivitas menyebut asma Allah SWT. Bertujuan untuk mendekatkan diri kepadanya, dengan membaca doa bersalawat, memohon ampunan kepada Allah SWT, untuk selalu mengingat akan kekuasaan dan kebesarannya sehingga kita bisa terhindar dari hal-hal buruk didunia.

2. Meudikee Anggok adalah berdzikir sambil angguk kepala, terdapat di dalam Dikee Molod yaitu sebuah kebiasaan agama Islam di Aceh untuk memperingati hari kelahiran nabi Muhammad SAW, yang biasanya disebut Maulid.
3. Meudikee Anggok merupakan tari kelompok yang ditarikan oleh 20- puluhan penari lakilaki, dengan memiliki gerakan unik dan menjadi ciri khas yaitu gerakan bahu dan kepala.

4. Secara estetika dalam Meudikee Anggok dapat kita lihat pada gerak, busana dan syair, yang dilihat di Dayah Darul Huda Desa Bayi Kecamatan Tanah Luas Lhoksukon Kabupaten Aceh Utara, secara estetika Meudikee Anggok bukan hanya diamati dari sisi keindahan saja, tetapi juga diamati dari rasa kecintaan yang terkandung di dalam Meudikee Anggok.

\section{Saran}

Berdasarkan hasil penelitian dapat diajukan beberapa saran, yaitu:

1. Dengan adanya penelitian Meudikee Anggok di Dayah Darul Huda Desa Bayi Kecamatan Tanah Luas Lhoksukon Kabupaten Aceh Utara, menyarankan kepada pemerintah Kebupaten Aceh Utara agar lebih memperhatikan dan berupaya melestarikan kesenian-kesenian di Kabupaten Aceh Utara.

2. Dengan penelitian ini, menyarankan kepada pemerintah agar memberikan wahana atau tempat para seniman-seniman Aceh untuk menuangkan ide-ide kreatif mereka.

3. Mengharapkan kepada para putra/putri Aceh tepatnya yang berada di Kabupaten Aceh Utara agar lebih peduli dan mencintai kesenian-kesenian asli di Aceh.

4. Menghimbau kepada masyarakat agar terus berupaya melestarikan kesenian-kesenian Aceh, dengan cara mengundang groub 
kesenian pada acara-acara yang mereka adakan.

5. Menghimbau kepada para pemerintah, putra/putri Aceh dan semua kalangan masyarakat untuk tidak pernah malu mengakui budaya Aceh dan terus mengembangkannya dimana pun mereka berada.

\section{DAFTAR PUSTAKA}

Atlas Fakhrunisa, 2016. Tari Ratoeh Duek Persfektif Nilai Estetika Islam. Ejournal of unimed. Gesture : jurnal Seni Tari.

Bertens K, 1993. Etika. PT. Kansius : Jakarta

Dharsono, 2007. Estetika: Bandung. PT Rekayasa Sony Kartika.

I Made Wirartha, 2006. Metode Penulisan. Yogyakarta.

Koenjtaningrat, 1985. Kebudayaan Indonesia : Jakarta. PT Rahekka.

Kumala Rafika, 2016. Nilai Sosial dan Estetika Tari Menganyam Purun Pada Masyarakat Kuala Begumit Kabupaten Langkat, Skripsi pada Universitas Negeri Medan: Tidak diterbitkan.

Macayus, 2008. Bentuk-Bentuk Kesenian : Jakarta PT Rineka Cipta.

Nasution S, 1983. Metode Penelitian Kualitatif. Bandung : Tariso.

Notoatmodjo, Soekidjo. 2005. Metodologi Penelitian Kesehatan. Cetakan 3: Jakarta. Rineka Cipta.

Prihatin, 2008. Bentuk dan Fungsi Kesenian. USU. Institusional Respository.
Ramadiana, Nur Sari, 2017. Nilai Etika dan Estetika Tari Ratoeh Pada Masyarakat Aceh di Kota Langsa, Skripsi pada Universitas Negeri Medan.

Saadah, 2014. Etika dan Estetika tari Guel Di Masyarakat Gayo Aceh Tengah. Skripsi pada Universitas Negeri Medan.

Sirait Vivi Aulia, 2017. Etika dan Estetika Tari Gambus Delapan Pada Masyarakat Selimbat Kecamatan Selesai. Skripsi Universitas Negeri Medan.

Soedarsono, 1986. Pengantar Pengetahuan dan Komposisi Tari. Yogyakarta: ASTI.

Sudjana Nana, 1988. Tuntutan Karya Ilmiah: Jakarta. Pustaka AZ

Sumardjo Jakob, 1999. Filsafat Seni. Bandung. PT ITB Bandung. 